\title{
A Survey of Laryngological Surgeries As Seen in Two Centres in A Resource Poor Country
}

\author{
Onotai LO* and Ureh Oparaodu \\ Department of ENT Surgery, UPTH, Port Harcourt, Africa
}

Submission: February 12, 2017; Published: February 22, 2017

*Corresponding author: Onotai LO, Department of ENT Surgery, UPTH, Port Harcourt, Nigeria, Africa, Tel: 234803 3088861; Email: onotailuckinx@yahoo.co.uk

\begin{abstract}
Background: Several patients with otolaryngological diseases more often than not present as emergency to the otolaryngologists as a result of laryngologic diseases that require surgical interventions. This study is aimed at determining the types of laryngological surgeries as seen in 2 centres in Port Harcourt. It will also highlight the challenges encountered during the management of these patients.

Patients and methods: This was a retrospective study of patients who had laryngological surgeries both in the department of Ear Nose and Throat (ENT) surgery of the University of Port Harcourt Teaching Hospital (UPTH), Port Harcourt and Kinx Medical Consutants' clinic in Port Harcourt from January 2008 to January 2013. The patient's data were retrieved from the theatre and clinic registers. The patients' case notes were used to augment the data. Demographic data, clinical presentations, types of laryngologic surgeries, indication for surgeries, outcome of surgeries and complications were recorded and analyzed.

Results: One hundred and forty six patients had laryngological surgeries during the study period out of 455 otolaryngological procedures carried out during the period. This gives a prevalence of 32.09\%. There were 81 males and 65 females (male: female ratio of 1.2:1.0). Age range was 2 months to 80 years, mean $=16.4+/-12.2$ years. Age group $0-15$ years has the highest $(n=90)$ number of surgeries. The commonest laryngologic surgery done was direct laryngoscopy + removal of foreign bodies $n=75$. This was followed by tracheostomy $n=55$. The commonest indication for surgery was upper airway obstruction $n=97$.

Conclusion: This study highlighted our experience with laryngological surgeries as seen in 2 centres in Port Harcourt, Nigeria. Direct laryngoscopy + extraction of foreign body and tracheostomy were the commonest laryngologic surgeries encountered in our series. Public enlightenment campaign will help reduce the indications for laryngologic surgeries in our environment.

Keywords: Laryngological surgeries; Direct laryngoscopy; Tracheostomy; Upper airway obstruction; Total laryngectomy
\end{abstract}

\section{Introduction}

Laryngology encompasses clinical and surgical treatment of the diseases of the larynx and its related structures. It is an emergent subspecialty with advances in the surgical, clinical, and research realms1. A laryngologist is a board-certified otolaryngologist (ear, nose, and throat physician) who subspecializes in the diagnosis and management of diseases of the larynx, as well as disorders of the voice. Laryngologists receive intensive training on the medical and minimally invasive surgical treatment of laryngeal disorders including micro-laryngoscopy, laryngeal frame work surgeries, laryngeal polyps, nodules, neoplasm, voice disorders, vocal cord paralysis, swallowing disorders and voice rehabilitation. Laryngologists are experts in endoscopic procedures [1].

Patients with laryngological complaints account for a significant number of ENT ailments in our environment [2], especially in paediatric patients who aspirated foreign bodies that are lodged in the larynx. Non specific laryngitis and laryngopharyngeal reflux disease are very common conditions encountered by otorhinolaryngologists all over the world [35]. Hoarseness and chronic irritation of the throat are also very common symptoms of laryngologic diseases in our environment. Whereas, a few cases are amenable to medical treatment, a significant proportion of laryngologic diseases will require surgical intervention [1].

Newer surgical techniques including various forms of endoscopic sinus surgeries are now commonplace in the developed countries. However, laryngology practice in Nigeria as in most developing countries has been hampered by inadequacy of proper diagnostic and therapeutic facilities as well as poor training facilities for the upcoming otolaryngologist $[1,3,5]$. The University of Port Harcourt Teaching Hospital is a tertiary healthcare facility in the Niger-Delta region of Southern Nigeria and serves as a referral centre to primary, secondary and other tertiary health facilities in the region. 


\section{Global Journal of Otolaryngology}

Knowledge of the pattern of laryngologic surgeries in our environment will help draw attention to the challenges in the practice of laryngology and encourage funding for the training of laryngologists. This will lessen the current high trend of medical tourism with its consequent economic burden. This study is aimed at determining the types of laryngological surgeries as seen in 2 centres in Port Harcourt, Nigeria. It will also highlight the challenges encountered during the management of these patients.

\section{Patients and Methods}

This was a retrospective study of patients who had laryngological surgeries both in the department of Ear Nose and Throat (ENT) surgery of the University of Port Harcourt Teaching Hospital (UPTH), Port Harcourt and Kinx Medical Consultants' clinic in Port Harcourt from January 2008 to January 2013. The patient's data were retrieved from the theatre and clinic registers. The patients' case notes were used to augment the data. Demographic data, clinical presentations, types of laryngological surgeries, indication for surgeries, outcome of surgeries and complications were recorded. The data were entered into an
SPSS version 14 computer soft ware and analyzed descriptively.

\section{Results}

One hundred and forty six patients had laryngological surgeries during the study period out of 455 otolaryngological procedures carried out during the period. This gives a prevalence of $32.09 \%$. There were 81 males and 65 females (male: female ratio of 1.2:1.0). Age range was 2 months to 80 years, mean $=$ $16.4+/-12.2$ years. Age group $0-15$ years has the highest $(n=90)$ number of surgeries (Table 1). The commonest laryngologic surgery done was direct laryngoscopy + removal of foreign bodies from the laryn $x=75$. This was followed by tracheostomy $\mathrm{n}=55$ (Table 2). The commonest indication for surgery was upper airway obstruction $n=97$. Hoarseness $n=36$, chronic irritation of the throat $n=7$, feeling of a lump in the throat $n=6$ (Figure 1 ). The complications encountered were primary haemorrhage $\mathrm{n}=8$, cardiac arrest $\mathrm{n}=4$ and difficulty in decannulation $\mathrm{n}=14$. Mortality was recorded in 2 cases (Figure 2). Majority of the patients had good outcome following surgery $n=125$. Challenges encountered were: lack of appropriate instruments, late presentation of patients (after 72 hours), poverty and ignorance.

Table 1: Age range of patients.

\begin{tabular}{|c|c|c|}
\hline Age range (years) & Number & Percentage (\%) \\
\hline $0-15$ & 90 & 17.12 \\
\hline $16-30$ & 25 & 9.59 \\
\hline $31-45$ & 14 & 6.85 \\
\hline $46-60$ & 10 & 2.74 \\
\hline $61-75$ & 4 & 2.05 \\
\hline $76-100$ & 3 & 100 \\
\hline
\end{tabular}

Table 2: Laryngological surgeries.

\begin{tabular}{|c|c|c|}
\hline Laryngological surgeries & Number & Percentage (\%) \\
\hline $\begin{array}{c}\text { Direct laryngoscopy + removal of foreign body } \\
\text { from the larynx }\end{array}$ & 75 & 31.39 \\
\hline Tracheostomy & 55 & 1.37 \\
\hline Total Laryngectomy & 2 & 6.85 \\
\hline Direct laryngoscopy + biopsy & 10 & 2.74 \\
\hline Excision of laryngeal pappilloma & 4 & 100 \\
\hline Total & 146 & \\
\hline
\end{tabular}




\section{Global Journal of Otolaryngology}

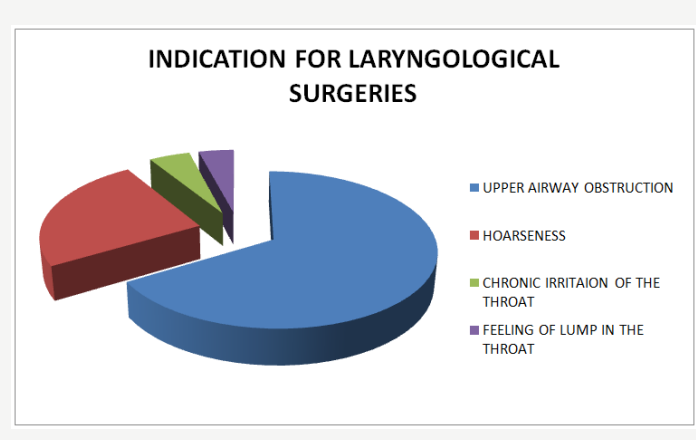

Figure 1: Indications for laryngological surgeries.

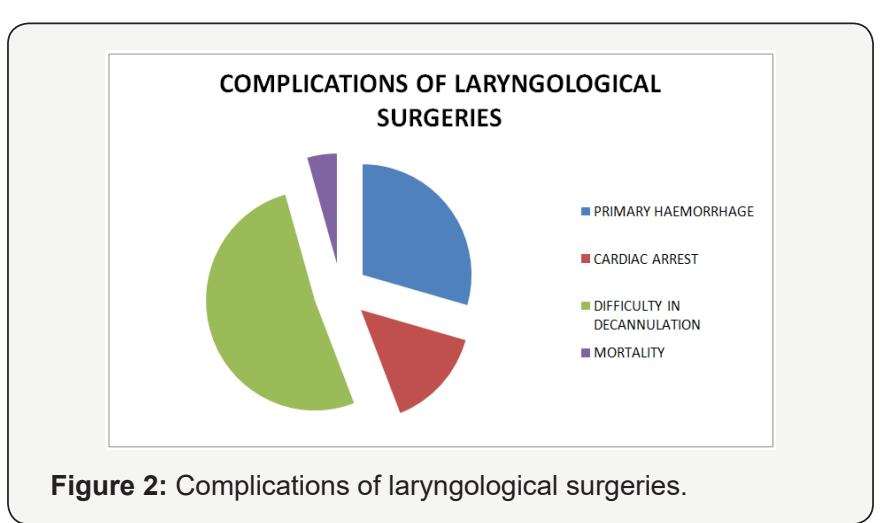

\section{Discussion}

The variety of surgical operations carried out in any centre depend on the surgical skill available, the volume of patients, the availability of appropriate facilities and the cost of the procedure $[1,6]$. Laryngological surgeries in this study accounted for $32.09 \%$ of the total otolaryngological surgeries carried out in both centres. da Lilly-Tariah and Peterside in 2008 in their evaluation of the scope of ear nose and throat surgeries in the theatre of University of Port Harcourt Teaching Hospital [5] found laryngological surgeries to be among the common surgeries done in their series.

Our prevalence of laryngological surgeries is higher than what Adoga et al found in Jos in their study of Audit of Otorhinolaryngological Practice in a Nigerian Teaching Hospital in Jos in 2008 [4] probably because we considered only laryngological procedures in our series besides, the duration of our study which was 5 years as against thiers which was done over a period of one year [4]. The male female ratio of 1.2:1.0 showed a slight male preponderance of laryngological surgeries in our series. This finding is similar to that of other researchers even though their study was not limited to only laryngological surgeries [2-5].

The age group that has the highest number of cases was 0-15 years. In this age group we had children who aspirated foreign bodies that were lodged in their larynx and direct laryngoscopy and extraction of foreign bodies were carried out on them. Some of the patients had tracheostomy procedure carried out on them either before the extraction or after the extraction of the foreign bodies. This mode of treatment has been documented by other researchers within our sub region [2-5]. Direct laryngoscopy and extraction of foreign bodies was the commonest procedure down in our series. This is not a surprise because the commonest age group we encountered was 0-15 years. Children have been reported to have the highest incidence of foreign body aspirations $[2,3]$.

The patients who are above 60 years of age represented the senior citizens in our series. They had the least laryngological procedures. Two of them had advanced laryngeal tumour and total laryngectomy was carried out on them. Our experience in the 2 centres does not differ from what was obtainable elsewhere within our environment. However, in developed countries microlaryngoscopy, various types of laryngeal frame work surgeries and phonosurgery are common place [1].

The commonest indication for laryngological surgeries we found was upper airway obstruction due to foreign body aspirations and laryngeal tumours. Most of the children with foreign body impaction in their larynx presented to us late (after 72 hours). Sometimes delay could be as a result of wrong diagnosis and wrong treatment given to the patients by the general practitioners. Another reason for their late presentation was ignorance and poverty. Because of the high cost of treatment in specialist hospitals patients tend to present first to non specialists for treatment. It's only when their condition become worst they decide to seek help in the specialist hospitals $[2,3,5]$.

At presentation majority of the patients with aspirated foreign bodies has features off acute upper airway obstruction because of the impaction of foreign body and the resultant edema of the larynx. It is very important to secure the airway first by performing emergency tracheostomy before attempting to carry out direct laryngoscopy and extraction of foreign body from the larynx. This mode of treatment agrees with the work done by Onotai et al. [2,3] in their study of impacted foreign bodies in the larynx of Nigerian children and that of Ibekwe et al., in their study of foreign bodies in the Ear, Nose and Throat in children: a five year review in Niger Delta.

The commonest complication we encountered in our study was difficulty in decannulation. This arose from injury of the foreign bodies to the cricoids cartilage and from complications of the emergency tracheostomy. Unfortunately, patients with laryngeal stenosis could not be managed in our centres due to lack of appropriate facilities and as such they were referred to other centres for further expert management. Onotai and Etawo had similar experience in their series in Port Harcourt 5 years ago [7]. Out of the 4 patients who developed cardiac arrest in our series, mortality occurred in 2 of them because of tracheostomy tube dislodgment post operatively. The other 2 patients developed cardiac arrest during the administration of aneasthesia and were successfully resuscitated. Although, minimal invasive surgery is the current trend in surgical practice 
and some endoscopic surgical equipment with camera are indispensible in most laryngological surgeries we are still yet to acquire them due to poor resources in our centres $[1,2,3]$.

\section{Conclusion}

This study has established the types of laryngological surgeries as seen in two specialist centres in Port Harcourt, Nigeria. The commonest laryngological surgery carried out was direct laryngoscopy either for extraction of foreign bodies or for biopsy. The scope of laryngological surgeries in our centres was limited to the available facilities and expertise. It is therefore, pertinent that adequate funding of health care facilities and training be provided by the government. The provision of modern equipments for laryngological surgeries coupled with more training of otolaryngologist will help reduce the burden of laryngological diseases in our environment.

\section{References}

1. Laryngology \& Larynx disorders Cleveland clinic.
2. Onotai LO, Ibekwe MU, George I (2012) Impacted foreign bodies in the larynx of Nigerian children. Journal of Medicine and Medical Sciences 3(4): 217-221.

3. Ibekwe MU, Onotai LO, Otaigbe B (2012) Foreign bodies in the Ear, Nose and Throat in children: a five year review in Niger Delta. African Journal of Paediatric Surgery 9(1): 3-7.

4. Adoga A, Nimkur T, Adekwu A, Ma'an N (2009) An Audit of Otorhinolaryngological Practice in a Nigerian Teaching Hospital. Internet J Otorhinolaryngol 9(1): 1-4.

5. da Lilly-Tariah OB, Peterside OA (2008) The Scope of Ear, Nose and Throat Surgeries In The Theatre of University Of Port Harcourt Teaching Hospital. Journal of Medice in the Tropics 10(1): 15-22.

6. Lasisi O (2007) Otolaryngological Practice in the Tropics: A Profile of Met And Unmet Needs. The Internet Journal of Otorhinolaryngology $7(2): 1-4$.

7. Onotai LO, Etawo US (2012) An Audit of Paediatric Tracheostomies in Port Harcourt Nigeria. International Journal of Medicine and Medical Sciences 2(7): 148-153.

\section{Your next submission with Juniper Publishers will reach you the below assets}

- Quality Editorial service

- Swift Peer Review

- Reprints availability

- E-prints Service

- Manuscript Podcast for convenient understanding

- Global attainment for your research

- Manuscript accessibility in different formats ( Pdf, E-pub, Full Text, Audio)

- Unceasing customer service

Track the below URL for one-step submission https://juniperpublishers.com/online-submission.php 